\section{A strategy is necessary. The policy-client conflict within different relational asymmetries: a comparison at the street-level}

SLBs' strategies within relational asymmetries

\author{
Daniela Leonardi \\ Università degli Studi di Parma, Parma, Italy \\ Rebecca Paraciani \\ Università Cattolica del Sacro Cuore, Milano, Italy, and \\ Dario Raspanti \\ Università degli Studi di Firenze, Florence, Italy
}

Received 29 July 2021 Revised 13 September 2021 Accepted 13 September 2021

\begin{abstract}
Purpose - This study aims to investigate the role of relational asymmetries in influencing the coping strategies adopted by frontline workers to deal with the policy-client role conflict.

Design/methodology/approach - A comparative analysis of three different services highlights the role of the service relationships characteristics in explaining similarities and differences in the strategies adopted by street-level bureaucrats (SLBs). The research is based on the secondary analysis of three case studies conducted in Italy: the reception system for homeless people, the job brokerage service in the public employment service and the dispute settlement procedure in the labour inspectorate.

Findings - The results underline the interaction between the characteristics of the service relationship and the different coping strategies adopted to deal with the policy-client conflict.

Originality/value - The contribution of this study is threefold. Firstly, the authors focus on the influence of the characteristics of the service relationship in terms of agency resources over SLBs' strategies to face with users' expectations. Secondly, the authors intend to discuss these issues analysing SLBs not only as agents with individual preferences. Thirdly, the research design allows the authors to return to the street-level bureaucracy theory its comparative essence, proposing a comparative strategy with an explorative intent.
\end{abstract}

Keywords Public policy, Qualitative method, Street-level bureaucracy, Policy-client conflict, Secondary analysis Paper type Research paper

\section{Introduction}

Public service delivery takes shape in the relationship between street-level bureaucrats (SLBs) and clients (Brodkin, 2011; Bruhn and Ekstrom, 2017; Dubois, 2010; Lipsky, 2010 (1980)). SLBs should be responsive to client demands and expectations while applying rules and regulations to interpret policy content. When policy content and client expectations collide, SLBs experience a policy-client role conflict (Tummers et al., 2012). Role conflicts affect policy implementation with negative consequences on service effectiveness, the

(c) Daniela Leonardi, Rebecca Paraciani and Dario Raspanti. Published by Emerald Publishing Limited. This article is published under the Creative Commons Attribution (CC BY 4.0) licence. Anyone may reproduce, distribute, translate and create derivative works of this article (for both commercial and noncommercial purposes), subject to full attribution to the original publication and authors. The full terms of this licence may be seen at http://creativecommons.org/licences/by/4.0/legalcode

The authors would like to thank Professor Evelyn Z. Brodkin for the careful reading and public discussion of this article in its early stages. The authors also thank Professor Rik van Berkel, Dr. Tatiana Saruis and Professor Sandro Busso for their reading and important feedback. The authors gratefully acknowledge constructive comments from five anonymous reviewers.

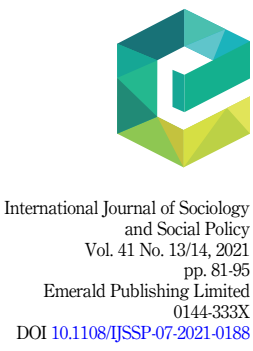


IJSSP

$41,13 / 14$ conception of their duties and client evaluations of the public administration (Tubre and Collins, 2000; Tummers and Bekkers, 2014; Zacka, 2017).

While role conflicts in bureaucratic relationships can be managed by relying on authority resources because of the SLB's position (Lipksy, 2010(1980); Dubois, 2014), service provision also comprises cooperative (Raaphorst and Loyens, 2020), participative (Aschhoff and Vogel, 2018) and market-like (Cohen et al., 2016; Thomann et al., 2018) arrangements that reduce the SLB's authoritative ability to control the service encounter unilaterally. Several studies put the characteristics of this service relationship at the centre of an analysis of SLB practices (Bartels, 2013). An SLB experiences action uncertainties regarding the ability to steer client interaction (Raaphorst, 2018). Solutions to reduce uncertainty and regain control over the relationship must be found in the SLB's negotiation and communication skills (Bartels, 2014; Raspanti and Saruis, 2021). SLBs base their decisions on how to service clients by collecting information (Lipsky, 2010(1980)), forming perceptions on client deservingness of support (Davidovitz and Cohen, 2020; Jilke and Tummers, 2018) and categorising clients according to their trustworthiness (Raaphorst and Groeneveld, 2018) during talks with clients. Scholars developed a rich array of coping strategies according to different discretionary applications of regulations (Hupe, 2013; Kazepov and Barberis, 2013), behavioural and cognitive coping (Tummers et al., 2015) and interaction styles (Van Parys and Struyven, 2018). Based on a literature review, this study identifies four types of strategies that deal with the policy-client role conflict: rejection, adaptation, teaching and negotiation.

This article will explore how the characteristics of the service relationship affect SLB coping strategies to deal with conflict in the policy-client role. The study has identified three different relational asymmetries according to the distribution of power resources between clients and SLBs. Firstly, in the "traditional" asymmetry, SLBs perform a gatekeeping function as they regulate a claimant's access to public resources (Lipsky, 1980(2010)). SLBs rely on the authority given by their position to establish sanctions and rewards for managing client requests. Secondly, the "reverse asymmetric" relationship characterises market-like environments where clients voluntarily choose to address the public provider instead of other kinds of providers (Cohen et al., 2016; Thomann et al., 2018; Raspanti, 2019). Profit and nonprofit providers and informal labour-intermediation channels have complemented the public provision of brokerage services. SLBs thus compete with non-public frontline workers to attract clients. Thirdly, the "symmetric" relationship where SLBs play an intermediate role in resolving a dispute between two opposing parties. Here, SLBs deal simultaneously with workers' and employers' requests (Paraciani, 2020).

The main research questions follow. Firstly, how do relational asymmetries within the service relationship influence the strategies adopted by SLBs to deal with the policy-client conflict? Secondly, which strategy type relates to each service relationship?

Drawing on a comparative research design of three independent case studies conducted in Italy, the study argues that SLBs behavioural strategies are affected by the distribution of power among the actors of the bureaucratic relationship. We expect that the same strategy assumes peculiar nuances according to whether the service relationship is asymmetrical, symmetrical or reverse asymmetrical.

This study contributes to understanding the service delivery processes from a street-level perspective in three ways. Firstly, the study has focused its analysis on the characteristics of the service relationship. A growing literature addresses the service relationship as a distinct phenomenon (Bartels, 2013; Raaphorst and Loyens, 2020). In this view, SLBs decisions are not only the result of individual preferences as mediated by contextual pressure but part of the relationship with their clients. This study expands this approach, focusing on power imbalances between users and SLBs. It thus offers a threefold conceptualisation of service relationships as traditional, reverse asymmetric and symmetric according to the SLB's leeway in controlling the interaction. Secondly, the research design allows the authors to 
return its comparative nature to the SLB theory, proposing a comparative strategy with an exploratory intent. Maynard-Moody and Musheno (2003) use a comparative approach showing how different SLBs generate different SBL-client interactions through diverse interests and escalated conflicts. Hill and Hupe (2019) underline both the need and difficulty of conducting comparative research on street-level bureaucracies due to the strong local roots of service provision. They elaborate on the concept of a "public service gap" to overcome this obstacle and facilitate comparison. Paraciani and Saruis (2019) introduce the concept of "light" comparison, which compares exclusively caseworker narratives collected in two different institutional contexts. However, the lack of comparative research in this field of study is still present (Hupe et al., 2015). Thirdly, street-level research in Italy has only caught on in recent years with a considerable delay compared to North European or American scholars. It thus appears to be paradoxical because the Italian case offers a very promising study from this perspective, given the complex articulation and fragmentation of the welfare system (Barberis et al., 2019). The study thus contributes to the diffusion of the street-level bureaucracy approach in an understudied context.

\section{Literature review: role conflicts and coping strategies}

\subsection{Role conflicts at the street-level}

Role conflicts emerge when an agent is subject to different expectations and demands that push in diverging directions, causing stress and behavioural ambiguity in frontline workers (Zacka, 2017). Vink et al. (2015) identify four types of role conflicts. Firstly, the policy-professional conflict indicates an incompatibility between policy content and the values, norms and behavioural guidelines that define an SLB's professional identity. Secondly, the organisational-professional role conflict relates to the professional habitus and how a particular organisation expects the frontline worker to perform the service. This type of conflict is related to the former; however, it is logically independent because it relates to a manager's ability to emphasise specific policy content or organisational goals over others. SLBs are asked to pursue executive directives, such as efficiency improvement, cost containment, clients' processing pace, which may collide with professional norms. Thirdly, the professional-client role conflict represents potential tensions between professional norms and client expectations in the service, such as, for instance, a patient asking for euthanasia (Vink et al., 2015).

This study focuses on the fourth type: the policy-client role conflict. This type of conflict occurs when professionals tasked with implementing a policy perceive the role behaviour demanded by their clients to be incongruent with the role behaviour demanded by the policy content. An extreme example regards the police officers who must implement stricter law enforcement, such as zero-tolerance policies. As Lipsky notes, these police officers "must enforce laws they did not make in communities where demands for law enforcement vary with the laws and the various strata of the population" (Lipsky, 2010(1980), p. 47). As a result, enforcing zerotolerance, in line with the policy content, can conflict seriously with the role behaviour demanded by clients, who want police officers to take account of their specific circumstances.

\subsection{Strategies for dealing with role conflicts}

The literature stresses the importance of studying SLBs' coping strategies in dealing with conflicting demands from clients and norms to understand service delivery success and deficiencies (Zacka, 2017). SLBs can act with autonomy in deciding how to service clients. The translation of standardised rules to actual conditions needs a certain degree of autonomy when deliberating on clients' access to public services (Evans and Harris, 2004). Such autonomy is not necessarily conducive to negative consequences for individual claimants. Still, it is often used to ease service delivery and solve implementation dilemmas (Lipsky, 2010(1980)), like role conflicts (Vink et al., 2015). Reviewing the literature, four ideal-typical strategies for dealing with the policy-client role conflict emerge: rejection, adaptation, teaching and negotiation. 
IJSSP

$41,13 / 14$

According to Tummers et al. (2015), rejection is the most common SLB coping strategy. It indicates the refusal of the policy-client conflict or its consequences by distancing the responsibilities attached to their role. Consequently, SLBs reject to deal with role conflicts when they delegate the responsibility to manage conflict to higher roles in the bureaucratic hierarchy, even when the delegation is merely nominal (De Graaf et al., 2016; Vink et al., 2015). Other instances of rejection are the SLB's adoption of a strict rule-following behaviour (Soss et al., 2011) or reliance on routine practices, i.e., as the "complete detachment and the comfort of routine anonymity" (Dubois, 2010, p. 74). Davidovitz and Cohen (2020) have labelled this "self-defense" strategy since SLBs act cautiously to protect themselves from the threats inherent in the relationship with clients. Summing up, rejection is a non-engagement of the policy-client conflict to avoid the additional costs of conflict.

When the policy-client conflict is addressed with actions adapted to the broad and general rule of the client's expectations, by de facto favouring certain clients or client groups over others, it is possible to identify an adaptation suitable to the client's expectations. As a result, SLBs bend or break rules to accommodate regulations and client requests or needs (May and Winter, 2012). Examples of "adaptation" are turning a blind eye (Raaphorst and Loyens, 2020), finding alternative solutions to procedure-following strategies (Cohen et al., 2016; Ingold, 2018; Raspanti and Saruis, 2021) and negative consequences of alleviating procedures for clients (Dubois, 2010). SLBs tend to resolve the policy-client conflict by choosing the best solution to reduce the client discontent (Tummers et al., 2015).

The third strategy, teaching, combines two different behaviours: "coaching" and "disciplining". Firstly, SLBs manage the conflict by coaching clients on handling regulations to solve their discomfort with service outputs by explaining service constraints and opportunities or proper behaviour according to service requirements. Coaching aims to improve a client's relationship with the public service (Aksnes, 2019) or advocate their rights before a public administration (Zacka, 2017). Secondly, teaching also emerges as disciplining, i.e. exerting enforcement from deploying symbolic or financial sanctions and rewards (Lipsy, 2010(1980); Møller and Stone, 2013; Senghaas et al., 2019) up to using violence or aggression with the users (Brown, 1988; Maynard-Moody and Muscheno, 2003).

Negotiation appears when the SLBs cope with the client's discontent by discussing the situation and the possible solution with him/her in order to reach a shared one. In such services, like co-production arrangements (Aschhoff and Vogel, 2018), where cooperation and the client's willingness to work together play a fundamental part in service implementation (Senghaas et al., 2019), negotiation appears to be a viable strategy to conflict resolution, e.g. in conciliation justice (Raaphorst and Loyens, 2020; Tuurnas et al., 2016) or employer-oriented services (Aksnes, 2019; Raspanti and Saruis, 2021). However, negotiation may also emerge in less rule-governed services, where SLBs are vested with discretion by the rules (Mik-Meyers and Silverman, 2019). For example, Bruhn and Ekström (2017) found that rules are negotiated even within the traditional relationship between caseworkers and students applying for loans.

\section{Case study descriptions}

The study builds on three case studies conducted in different public services in Italy. The research design compares three types of service relationships: traditional asymmetric, reverse asymmetric and symmetric. The first case study covers a traditional relationship between homeless people and night shelter workers who manage access to the night facilities where homeless people may rest until the early morning. The second case study represents an instance of a reverse asymmetric relationship. It is conducted in the public employment service (PES) where job-brokers deal with employers in supporting the recruitment process of 
new workers. The third case study is about labour inspectors who mediate between employers and workers to find an administrative solution to employment disputes. Finally, the case study covers a symmetrical relationship. The present section offers an overview of these case studies.

\subsection{The homeless shelter reception system}

The first case study looks at the night shelters in Turin's homeless shelter reception system. The "staircase approach" is the prevalent paradigm adopted by the municipality to manage homelessness. In recent years, there have also been the Housing First projects, but they involve fewer beneficiaries (Lancione et al., 2018). The "staircase approach" envisages the homeless person moving in the shortest time from a series of precarious, emergency housing solutions to accommodations that guarantee an increased level of privacy and autonomy.

Since neither shelters nor housing solutions are sufficient to meet demand, frontline workers must assess which people should be allowed to advance along the path. They have to decide who should get what and why (van Oorschot, 2000). To do this, they must exercise their professional discretion (Leonardi, 2019). They develop distinctive ethical commitments to a certain way of performing the role (Zacka, 2017, p. 237), and, at the same time, SLBs are responsible for ensuring compliance with the rules. They must quickly resolve conflicts dilemmatic situations and work to encourage clients to cohabit peacefully. For many homeless people, the bureaucratic encounter with these services is the first contact with institutions. The client enters as a "claimant" to request services and has much at stake for the interaction's outcome.

In this scenario, the frontline worker's role assumes particular importance, as the complex interactions in the policy implementing process are influenced by their actions, decisions, ideals and beliefs. It is important to underline that the number of homeless people is growing in Italy (Consoli and Meo, 2021) and, with the number also growing in Turin [1], services are under pressure and available resources are insufficient. Consequently, help is often characterised as emergency assistance.

\subsection{The public employment service}

The second case study focuses on the job brokerage service implemented by the Tuscan Region's PES. In Tuscany, 41 local job centres provide employability services to the unemployed and employers. The job brokerage service is aimed at supporting employers in seeking and selecting new workers. Job brokers do the following tasks: identify the employer's needs in terms of skills, draft the job offer to be published on the public service's online job board and manage job seeker applications. Once the job ad has expired, the job broker selects the most suitable candidates and sends the curricula selected to the employer, who has the final say about the recruitment.

The relationship between job brokers and employers has the characteristics of a reverse asymmetrical relationship (Raspanti and Saruis, 2021). On the one hand, employers rely voluntarily on the PES because of the availability of alternative ways to recruit the workers they need (Raspanti, 2019). As opposed to unemployment benefit recipients, employers do not have any obligation concerning the job brokerage service. They can withdraw at any moment without formal sanctions nor costs since the service is cost-free, nor are they obliged to interview or recruit the candidates shortlisted by the job broker. On the other hand, job brokers need the employer's involvement in sharing information about the vacancy characteristics to accomplish the tasks related to the job brokerage service. Besides, the employers' recruitment decisions are crucial for the overall evaluation of the PES since the effectiveness of employability services is calculated by the number of recruited beneficiaries, increasing the job broker's dependency on employers. As a result, the employer's discretion reduces the job broker's autonomy in delivering the service. 
IJSSP

$41,13 / 14$

\subsection{The labour inspectorate}

The third case study was conducted in the local office of the Italian Labour Inspectorate (ILI) in Bologna. The ILI is a public agency that reports to the Ministry of Labour and Social Policy. The ministry has the responsibility for the managing, programming and coordination of inspection activities. The central office is in Rome, with 80 local offices distributed throughout Italy. The overall staff consists of 6,357 employees [2]. The data analysed was collected in the ILI's local office in Bologna. As a result of this reformative process, standardized strategies and fixed standard sets at a central level have been implemented in each local office (Borghi and van Berkel, 2007).

The present study focuses on the dispute settlement procedures, where the labour inspector plays an impartial role, acting based on employee statements to find an administrative solution that suits both clients: workers and employers. The dispute settlement procedure is a non-repressive instrument that can be used as an alternative to the traditional inspective activities. This preventive tool (offered to the worker at the time of the intervention request) has become the preferred solution since it offers a quick solution to an increased number of requests for intervention.

During this procedure, the labour inspector is an impartial third party who, based on employee statements, must find the best possible administrative solution for both parties. The employer is exempt from any sanctions by resolving the dispute at this stage (Paraciani and Rizza, 2019). Despite the growing standardization of practices, labour inspectors use their discretion, which translates into different ways of dealing with the specific inspectorworker-employer interaction and in variations in dispute management styles.

\section{Methods}

The paper draws on three independent case studies, all conducted in Italy in different streetlevel organisations. The data were collected as part of the authors' corresponding Ph.D. theses. Each study originally had its own research questions and purposes. Thus, the data were re-analysed to comply with this article's research questions. All three cases use documentary analysis and semi-structured interviews; ethnographies and vignette interviews complement data collection in the homeless shelters and labour inspectorate case studies.

In the homeless shelter system case study, 20 semi-structured interviews were collected with frontline workers, and eight months of participant observation were conducted in three night shelters and two welfare offices in Turin. Observation and conversation data were written down in detailed field notes, while formal interviews were audio-recorded, transcribed and analysed. The interviewees are welfare offices and shelters workers, case managers and policymakers for the Service for Adults in Difficulty. Their characteristics reflect the reference population in terms of gender, age, educational qualification and seniority of service.

In the PES study, the interviews took place in 10 regional job centres in the provinces of Florence and Prato in Tuscany. A total of 13 job brokers were interviewed: 8 women and 5 men. The average age is 48 . The most experienced job brokers have long careers in the public administration as social workers or with administrative tasks, not necessarily in the employment sector. The younger job brokers have extensive training and careers in labour intermediation.

The labour inspectorate study comprises nine months of participant observation in the ILI's local Bologna office, where 178 observations were conducted, and 231 work irregularities were observed. Of these, 43 were registered during the dispute settlement procedure and were analysed for this article. During this study, six different labour inspectors were observed, three women and three men. Four of them have more than 15 years 
of experience. Only two do not hold at least a bachelor's degree. During the nine months of participant observation, diaries were drafted and then added to the empirical materials.

Since data were collected for other purposes, all the materials were re-analysed using the qualitative data analysis software NVivo 12 to ensure rigour in qualitative data analysis (Maher et al., 2018). The analytical procedure followed four steps. For each step, each individual session of data analysis was then followed by a collective discussion of the results assembled to refine our interpretations.

Firstly, we individually re-analysed each case study interview to identify words and sentences that can be considered instances of the policy-client conflict. For example, the statement "I can't do as employment agencies do, downloading fifty curricula from the database every ten days to submit few of them to the employer. And the other ones? That would mean discriminating against whom's not flagged" indicates a policy-client conflict as experienced by a PES job broker.

Secondly, we focused on SLBs' reactions to policy-client conflict instances. The literature review discussed above informed the coding of the coping strategies. We deductively named the code labels "rejection", "adaptation", "teaching" and "negotiation". We then returned to the data to extrapolate the lines that could be considered instances of each coping strategy. Rejection was defined as "non-engaging in the policy-client conflict to avoid conflict costs." We defined the second strategy, adaption, as "actions that adapt the broad and general rule to a client's expectations at the expense of policy regulations". The third strategy was teaching, defined as "coaching or teaching the client regarding service procedures". The fourth strategy, negotiation, was defined as "discussing alternative solutions to the policy-client role conflict with the client".

Thirdly, we discuss the results of the individual coding procedures to reach a shared understanding of the characteristics of frontline-worker strategies. We compared each other's coding to refine our data interpretation. Data reliability was guaranteed since the questions asked of the interviewees were similar in the three case studies. The interviews focused on the interviewees' experiences with their clients and colleagues, the daily organisation of their tasks, their feelings about the policies they are mandated to implement and the organisational context.

\section{Strategies observed at the frontline}

As stated in the second section, four strategies for coping with role conflicts emerged from the literature review: rejection, adaptation to a client's expectations, teaching and negotiation. In the following, we report some examples of recurring strategies for coping with the policyclient role conflict as they appear in the case studies.

\subsection{Rejection}

Rejection is a strategy identified in all the case studies. SLBs refuse to cope with the policyclient conflict to protect themselves from the consequences of the conflict. In the following quotation, a frontline worker denies letting a homeless person sleep on the couch to avoid subsequent complaints from other clients. The conflict was determined by organisational shortcomings (i.e. the mismatch between the number of claimants and the supply of beds in the shelter) and resolved by transferring the negative consequences to the rejected claimant, who had to move elsewhere. The shelter worker justified the decision by referring to regulations.

Sometimes they ask you, “Can I sleep on the couch?”. Then you explain, "No, you can't, because we have rules on the [shelter's] capacity and fire safety, and so on" [...] Sometimes you must be strict because if I let you sleep on the couch since you did not find another place to stay, then the others will 
IJSSP

$41,13 / 14$

88 say "Why can she and not me? You must let me do it too!" and there will be problems from the next night onwards.

Job brokers adopt strict rule-following in two cases. Firstly, when a client's expectations are not met due to workloads. Refusing the conflict is selected when no other strategy is viable because of being too costly. Secondly, job brokers adopt rejection to face an employer's illegal requests to flag candidates according to prohibited criteria (e.g. sex and age). Rejection lets a confrontation be avoided that may negatively affect an employer's future involvement in service provision. Rejection as delegation is shown in the following excerpt from a field note referring to the dispute settlement procedure. The labour inspector ignored the report of more serious complaints by a domestic worker because not within his jurisdiction. Attempts to delegate responsibility to higher levels in the professional hierarchy served the purpose of the office.

During the interview, the domestic worker accused the employer (sitting next to her) to have abused her. The labour inspector interrupted the discussion and said she was not interested in the question: "We are here to find a solution for facts relating to the employment relationship. These things will be reported to those in charge".

\subsection{Adaptation}

Adaptation occurs when SLBs resolve the policy-client conflict by deciding on the solution that best reduces the client's discontent concerning service outputs. When the service relationship is asymmetrical, as in the shelter system for homeless people, this strategy manifests as (1) advocacy towards clients by promoting social justice, i.e. defending clients against service provision-related inequalities or (2) by "turning a blind eye" to noncompliance with regulations. In the following quotation, a homeless-shelter frontline worker allowed a client (Aldo) to sleep in the shelter, although he came back after opening time. The frontline worker reacted by adapting time regulation to the client:

It's true that he came back after the scheduled time, but it was late. Aldo was just coming back, and my colleague had left. It was better to turn a blind eye and suggest being punctual next time.

Adaptation assumes the same meaning in the dispute settlement procedure. Although the relationship is threefold (inspector-worker-employer), some labour inspectors tend to resolve the policy-client conflict by favouring the solution that reduces the worker's discontent. When they "turn a blind eye", they do it to please the weaker part of the relationship. The opposite, i.e. a decision in favour of the employer, was not observed.

Compared to the other two case studies, adaptation embraces a different meaning in the PES case study. Policy-client conflict may emerge in the case of an employer's need clashing with the service procedures. Job brokers may react by applying the employer's criteria to select the job seekers, even though they conflict with anti-discrimination rules or disrupt the service's procedures. The following quotation demonstrates why job brokers adapt to an employer's request, even deciding to subvert the job-offer routine management. In particular, the job brokers decided to anticipate the delivery of the candidates' curricula, although this is prohibited before job offer expires (typically, after one week). The rule avoids the "first come, first served" mechanism to guarantee equal opportunities to all the suitable candidates. However, the job broker reported that she would comply with the employer's need to speed up the recruitment process due to specific conditions:

If the employer says, "Look, another employee left the company. The production stopped. Could you please publish the job offer immediately? If someone applies, let me know", then in that case ... Because if we publish the offer for one week, and there is already a candidate after two days, that will mean not doing the employer a service because you could send him a suitable person. However, you 
reply with "No, we must wait for the expiration date". Then, in such cases, when the company says

"Look, I do not cope" we send the curricula in advance.

Since employers may rely on private providers or informal channels to recruit workers, job brokers struggle to comply with employers' request and a long-term perspective. Indeed, because employers' recruitment decisions increase employability services' effectiveness, job brokers may decide to break or bend service rules to achieve employers' compliance.

\subsection{Teaching}

Teaching is expressed through two different behaviours: "coaching" and "disciplining". In the first case, SLBs coach their clients on handling regulations to obtain what they are asking for by explaining service constraints and opportunities. The second strategy emerges as disciplining, i.e. explicit actions to control the client's behaviour by indicating the appropriate behaviours to follow.

In the case of the homeless shelter, the SLBs are in an asymmetrical position with clients and often adopt the teaching strategy with their clients in the form of disciplining to bring clients into compliance with the expectations of shelter services, as shown in this excerpt:

Anyone who comes to ask for a bed knows very well that we always are above-board about things. We do not accept any demands. There are no fixed hours; they just have to wait. Anyone who starts saying, "but what about my place?" I say, "Listen, your place may or may not be there. If you keep on like this, it will not be" because otherwise, you'll find people every three minutes saying: "What about my place?". We teach them how it works here.

Job brokers use teaching mainly as coaching. Indeed, they support employers by analysing their needs in terms of competencies and skills and drafting the job offer together. While coaching is also used by employers, it is likely applied to potential workers. Due to staff shortages, job brokers often meet with job seekers enrolled in training or job search support services. Thus, they train job seekers to introduce themselves to employers to maximise the possibility of being recruited, e.g. adopting the proper behaviour or emphasising relevant competencies and experience.

In some cases, coaching turns out to be implicit disciplining. The following quotation shows the difficulties minorities have in finding jobs due to mistrust related to their habits when looking for work with the public. The job broker says he suggested in a meeting to a hijab-wearing Muslim woman not to wear it during the job interview for a hairdresser's position:

We tried to make her [the Muslim girl] understand that if she wants to get that job, she will also have to decide. We have an Arabic cultural intermediator on Thursdays because many girls want to become beauticians or hairdressers. We say to them, "Look, you will face some difficulties [in finding a job]". So, if she continues to wear the hijab, she can. Then she will figure it out, and she will make her own decision. But you can't say to her, "No, you can't apply [for that job]”, God forbid!

In the labour inspectorate case study, this strategy has manifested only as disciplining. Inspectors do not regulate only the weaker part (i.e. the worker) or only the part perceived as being the stronger of the two (i.e. the employer), but this strategy is manifested towards both parts. As reported in the following field note, inspectors generally use disciplining to speed up the conciliation between the parties and reach an agreement. The aim is, therefore, to rapidly close the case, using the power of inspection as a "threat", as reported in the following quotation:

The inspector addressed the employer angrily, "I do not know how to reach you. If you do not cooperate, we can't do anything here. And if we do not find a solution, your company will be seriously inspected. Let's open that Pandora's box!"
SLBs'strategies within relational asymmetries 
IJSSP

$41,13 / 14$

90

\subsection{Negotiation}

Negotiation emerges when the SLBs have to cope with a client's dissatisfaction. The SLB discusses the situation and possible solutions directly with the client. In the reverse asymmetry relationship between job brokers and employers, negotiation is frequently deployed. Negotiation is one of the job broker's tools for gaining the employer's trust. As job brokers cannot impose their decisions on employers, the ability to find alternative solutions to the (frequent) mismatches between an employer's requests and a job seeker's skills is key to a frontline worker's job. During the labour demand analysis, job brokers may decide to intervene trying to modify the employer's requests, as shown in the following quotation. This serves two purposes. Firstly, it is aimed at achieving labour intermediation and an employer's satisfaction in service outputs. Secondly, job brokers often propose income benefits beneficiaries to the employer even though they do not fully match the job offer.

Sometimes, we need to negotiate. If you understand what the company does, maybe you can suggest an alternative solution if that job profile is missing. In my opinion, it's all about labour demand analysis.

In the labour inspectorate case study, where coaching did not occur, the negotiation strategy is at the basis of the service.

Here's the situation. in case of an inspection, you [the worker] will be wasting your time - given the conditions - unnecessarily, and you [the employer] risk other unpleasant things coming out. So, we arm ourselves with the patience to meet in the middle. In this way, you [the worker] will have something in a while, and you [the employer] will avoid sanctions and other things that can get you in trouble by regularising the relationship.

Unlike, as shown by other studies (Bruhn and Ekström, 2017; Mik-Meyers and Silverman, 2019), negotiation has not been observed in the traditional relationship characterising the shelter system for homeless people. In this case, frontline workers, acting as gatekeepers, implement relational modalities characterised by their informational asymmetry; therefore, they do not feel obliged to negotiate. They do not perceive themselves as being on the same level since the clients make the requests and the frontline workers approve or disapprove them.

\section{Discussion and conclusion}

This study represents an initial attempt to discuss the influences of the service encounter's relational components on the SLBs' coping strategies from a comparative point of view, opening a new debate on the role that the distribution of power resources could have in conflicting situations. The study has used the concept of "policy-client role conflict" (Vink et al., 2015) as an analytical tool to resolve difficulties linked to comparative street-level research (Hill and Hupe, 2019). Thanks to a literature review, four coping strategies were delineated: rejection, adaptation, teaching and negotiation.

The study uses a typology of service relationships based on the power distribution among the participants. The concept of power here expresses the possibility of an actor's ability to impose her decision on other actors and act free from others' decisions (Crozier and Friedberg, 1977). First, we identified a traditional asymmetric relationship where the SLBs could impose unilateral decisions on clients at lower costs. Within the "reverse asymmetric" relationship, the SLB rely significantly on clients' actions. For example, the client's withdrawal may follow a failure to adapt service content to the client's expectations. We then identify the symmetrical relationship, where the SLB acts as an intermediary between two clients.

The study demonstrates that a particular power distribution influences the SLB's behaviour in resolving a conflictual situation. Furthermore, findings show that a strategy assumes particular nuances when deployed in different power relationships. 
In all three cases, rejection appears to be related to contextual pressures. Rejection is deployed to handle workloads and red tape, and thus the costs caused by opening a conflict with clients on service content. This is certainly true for night-shelter workers. The use of discretion in an explicitly way also entails costs in terms of assuming responsibility. To reject, in this case, often means to refuse to assume those costs. In daily practice, regulations can protect the SLBs from "putting their face on it". In the other two cases, rejection is also deployed to pursue other purposes. Labour inspectors use rejection to facilitate an agreement between the parties by avoiding deviations from the procedures and the consequential waste of time. Control over the interaction is pursued by inviting the parties to focus on the procedures instead of fighting. In the reverse asymmetric relationship, rejection appeared to be used to control the negative consequences of a client's actions on service outcomes. Job brokers adopt a strict rule-following behaviour to avoid a direct confrontation with the employer who has indicated discriminatory criteria for the job recruitment. Contrary to Davidovitz and Cohen's conclusions (2020) regarding the consequences of trust on coping mechanisms, job brokers here tend to do less for untrustworthy clients. However, rejection is used not to directly face the merits of an employer's requests and thus continue the service relationship.

Adaptation assumes a crucial meaning in the asymmetric relationship. When the client can easily withdraw from the service relationship, SLBs use adaptation to compensate for their weak position. Solving the policy-client conflict towards clients may increase the probability of realizing the service in the short term and retaining the client on a long-term basis. In the other two relationships, adaptation has been observed as "turning a blind eye". For example, shelter workers overlook a guest's inappropriate behaviours to avoid sanctioning them with expulsion from the shelter. The use of discretion often has educational purposes and a willingness to help people in situations of extreme deprivation. However, when labour inspectors turn a blind eye, they do it to avoid possible tensions when "the serpent's head must be cut off" (Field Note).

Teaching may assume the characteristics of "coaching", i.e. SLBs supporting clients with service regulations or "disciplining", i.e. exerting compliance. In a traditional relationship, teaching assumes the traits of disciplining: SLBs' socialise the beneficiaries to the expectations of public services, while it is declined as coaching the asymmetric relationship. Job brokers coach employers to demonstrate how they may achieve more significant returns from service procedures. However, the boundaries between the two concepts tend to blur. When labour inspectors refuse to comply with a client's expectations, they adopt disciplining elements. In the reverse asymmetric relationship, when job brokers approach job seekers instead of employers, they use the coaching strategy to increase the possibility of finding a job. Because the relationship between job seekers and job brokers could be described as being biased towards the latter, the study shows that coaching could turn out to be disciplining.

The SLB's ability to impose unilateral decisions over clients made negotiation almost absent in the traditional relationship. Homeless shelter workers appear to use disciplining behaviour rather than negotiation. In the reverse asymmetric case, negotiation appears to be strictly related to both adaptation and rejection. On one hand, job brokers use negotiation to modify an employer's request and then adapt the service to their (changed) expectations. On the other, negotiation is used to modify an employer's discriminatory requirements instead of rejecting this source of conflict. Negotiation is part of the service itself in the symmetric relationship. Labour inspectors mediate between workers' and employers' needs. However, it should be noted that despite "negotiating a solution between the parties" is the essence of the procedure analysed, SLBs use a rejection strategy to discipline their clients and avoid following dispute settlement procedure purposes. 
IJSSP $41,13 / 14$

92

The study has several limitations linked to the explorative nature of our study. Firstly, the major limitation is that it is not the result of an ad hoc research design. Rather, it results from secondary data analysis, collected in separate projects, each with its own aims and methods. Secondly, we only interviewed SLBs from Italy. Further research should analyse whether our findings are relevant in other countries, especially non-Western countries, where the service relationships may be very different. Thirdly, the selected sample did not allow for the systematic manipulation of the gender question, so our findings do not consider this question. For the same reason, characteristics (gender, age and years of experience) of the SLBs were not systematically discussed. Future research could investigate, for example, how gender influences the service relationship or the type of policy-client conflict that occurs.

This paper shows the importance of considering the distribution of power resources to study frontline decision-making. The observed similarities and differences conclude that it is not so much the type of work carried out but rather the type of relationship asymmetries that generates differences in coping strategies.

From the point of view of policy indications, this study underlines the importance of paying attention to the type of different relational asymmetries if we want to change, encourage or improve the adoption of one particular set of coping strategies over others. Accordingly, more effort should be made to clarify and define different types of bureaucratic relationships in the legislation and better train SLBs in evaluating their situation.

\section{Notes}

1. As showed in the internal Service for Adults in Difficulty (SAD) report, in 2018, 2,236 homeless persons were recorded in night shelters compared to 1,857 in 2017.

2. See https://www.ispettorato.gov.it/it-it/studiestatistiche/Pagine/default.aspx

\section{References}

Aksnes, S.Y. (2019), "Engaging employers in vocational rehabilitation: understanding the new significance of knowledge brokers", Journal of Vocational Rehabilitation, Vol. 50 No. 5, pp. 73-84.

Aschhoff, N. and Vogel, R. (2018), "Value conflicts in co-production: governing public values in multiactor settings", International Journal of Public Sector Management, Vol. 31, pp. 775-793.

Barberis, E., Paraciani, R. and Saruis, T. (2019), "Nota introduttiva al focus", Politiche Sociali, Vol. 6, pp. 389-406.

Bartels, K.P.R. (2013), "Public encounters: the history and future of face-to-face contact between public professionals and citizens", Public Administration, Vol. 91 No. 2, pp. 469-483.

Bartels, K.P.R. (2014), "Communicative capacity: the added value of public encounters for participatory democracy”, American Review of Public Administration, Vol. 44 No. 6, pp. 656-674.

Borghi, V. and van Berkel, R. (2007), "Individualised service provision in an era of activation and new governance", International Journal of Sociology and Social Policy, Vol. 27 Nos 7-8, pp. 413-424.

Brodkin, E.Z. (2011), "Policy work: street-level organizations under new managerialism", Journal of Public Administration Research and Theory, Vol. 21, pp. i253-i277.

Brown, M.K. (1988), Working the Street: Police Discretion and the Dilemmas of Reform, Russell Sage Foundation, New York.

Bruhn, A. and Ekström, M. (2017), "Towards a multi-level approach on frontline interactions in the public sector: institutional transformations and the dynamics of real-time interactions", Social Policy and Administration, Vol. 51 No. 1, pp. 195-215.

Cohen, N., Benish, A. and Shamriz-Ilouz, A. (2016), "When the clients can choose: dilemmas of streetlevel workers in choice-based social services", Social Service Review, Vol. 90 No. 4, pp. 620-646. 
Consoli, T. and Meo, A. (2021), Homelessness in Italia: Biografie, territori, politiche, Franco Angeli, Milano.

Crozier, M. and Friedberg, E. (1977), L'acteur et le Systeme. Les contraintes de l'action collective, Editions du Seuil, Paris.

Davidovitz, M. and Cohen, N. (2020), "Playing defence: the impact of trust on the coping mechanisms of Street-level bureaucrats", Public Management Review, pp. 1-22. doi: 10.1080/14719037.2020. 1817532.

De Graaf, G., Huberts, L. and Smulders, R. (2016), “Coping with public value conflicts”, Administration

SLBs' strategies within relational asymmetries

Dubois, V. (2010), The Bureaucrat and the poor: Encounters in French Welfare Offices, Routledge, London, New York.

Dubois, V. (2014), “The state, legal rigor, and the poor. The daily practice of welfare control”, Social Analysis, Vol. 58 No. 3, pp. 38-55.

Evans, T. and Harris, J. (2004), "Street-level bureaucracy, social work and the (exaggerated) death of discretion", The British Journal of Social Work, Vol. 34 No. 6, pp. 871-895.

Hill, M. and Hupe, P. (2019), "Comparing public task performance", in Hupe, P. (Ed.), Research Handbook on Street-Level Bureaucracy. The Ground Floor of Government in Context, Edward Elgar, Cheltenham, pp. 282-293.

Hupe, P. (2013), "Dimensions of discretion: specifying the object of street-level bureaucracy research", Der Moderne Staat. Zeitschrift für Public Policy, Recht und Management, Vol. 6 No. 2, pp. $425-440$.

Hupe, P., Hill, M. and Buffat, A. (2015), "Conclusion: the present and future study of Street-level Bureaucracy", in Hupe, P., Hill, M. and Buffat, A. (Eds), Understanding Street-Level Bureaucracy, Policy Press, Chicago, pp. 315-338.

Ingold, J. (2018), "Employer engagement in active labour market programmes: the role of boundary spanners", Public Administration, Vol. 96 No. 4, pp. 1-14.

Jilke, S. and Tummers, L. (2018), "Which clients are deserving of help? A theoretical model and experimental test", Journal of Public Administration Research and Theory, Vol. 28 No. 2, pp. 226-238.

Kazepov, Y. and Barberis, E. (2013), "Social assistance governance in europe. Towards a multi-level perspective", in Marx, I. and Nelson, K. (Eds), Minimum Income Protection in Flux, Palgrave Macmillan, Basingstoke, pp. 217-248.

Lancione, M., Stefanizzi, A. and Gaboardi, M. (2018), "Passive adaptation or active engagement? The challenges of Housing First internationally and in the Italian case", Housing Studies, Vol. 33, pp. 40-57.

Leonardi, D. (2019), "Etichettare, valutare, scegliere. Spazi discrezionali in un disegno di intervento istituzionale", Autonomie locali e servizi sociali, Vol. 42, pp. 305-320.

Lipsky, M. (2010(1980)), Street-level Bureaucracy: Dilemmas of the Individual in Public Services, Russel Sage Foundation, New York.

Maher, C., Hadfield, M., Hutchings, M. and de Eyto, A. (2018), "Ensuring rigor in qualitative data analysis: a design research approach to coding combining NVivo with traditional material methods", International Journal of Qualitative Methods, Vol. 17 No. 1, pp. 1-17.

May, P.J. and Winter, S.C. (2012), "Regulatory enforcement styles", in Parker, C. and Nielsen, V.L. (Eds), Explaining Regulatory Compliance, Edwar Elgar, Cheltenham, pp. 222-244.

Maynard-Moody, S.W. and Musheno, M. (2003), Cops, teachers, Counselors: Stories from the Front Lines of public Service, University of Michigan Press, Ann Harbour.

Mik-Meyer, N. and Silverman, D. (2019), "Agency and clientship in public encounters: co-constructing 'neediness' and 'worthiness' in shelter placement meetings", The British Journal of Sociology, Vol. 70 No. 5, pp. 1640-1660. 
IJSSP $41,13 / 14$

Møller, M.Ø. and Stone, D. (2013), "Disciplining disability under Danish active labour market policy", Social Policy and Administration, Vol. 47 No. 5, pp. 586-604.

Paraciani, R. (2020), "Decidere quando è graveConsiderazioni sulla discrezionalità degli ispettori del lavoro in Italia e in Olanda”, Professionalità Studi, Vol. 3 No. 3, pp. 39-62.

Paraciani, R. and Rizza, R. (2019), "When the workplace is the home: labour inspectors' discretionary power in the field of domestic work-an institutional analysis", Journal of Public Policy, Vol. 41 No. 1, pp. 1-16.

Paraciani, R. and Saruis, T. (2019), "When the law is not enough. Caseworkers' ideas of justice in practices", Sociologia del Lavoro, Vol. 154, pp. 163-182.

Raaphorst, N. (2018), "How to prove, how to interpret and what to do? Uncertainty experiences of Street-level tax officials”, Public Management Review, Vol. 20 No. 4, pp. 485-502.

Raaphorst, N. and Groeneveld, S. (2018), "Double standards in frontline decision making: a theoretical and empirical exploration", Administration and Society, Vol. 50 No. 8, pp. 1175-1201.

Raaphorst, N. and Loyens, K. (2020), "From poker games to kitchen tables: how social dynamics affect frontline decision making", Administration and Society, Vol. 52 No. 1, pp. 31-56.

Raspanti, D. (2019), "Coping with a voluntary client. Frontline workers in public employment services dealing with employers' recruitment needs", Politiche Sociali, Vol. 6 No. 3, pp. 427-446.

Raspanti, D. and Saruis, T. (2021), "Trapped into reverse asymmetry: public employment services dealing with employers", Journal of Social Policy, pp. 1-18. doi: 10.1017/S0047279420000756.

Senghaas, M., Freier, C. and Kupka, P. (2019), "Practices of activation in frontline interactions: coercion, persuasion, and the role of trust in activation policies in Germany", Social Policy and Administration, Vol. 53 No. 5, pp. 613-626.

Soss, J., Fording, R. and Schram, S.F. (2011), "The organization of discipline: from performance management to perversity and punishment", Journal of Public Administration Research and Theory, Vol. 21 Suppl. 2, pp. i203-i232.

Thomann, E., Hupe, P. and Sager, F. (2018), "Serving many masters: public accountability in private policy implementation”, Governance, Vol. 31 No. 2, pp. 299-319.

Tubre, T.C. and Collins, J.M. (2000), "Jackson and schuler (1985) revisited: a meta-analysis of the relationships between role ambiguity, role conflict, and job performance", Journal of Management, Vol. 26 No. 1, pp. 155-169.

Tummers, L.G. and Bekkers, V. (2014), "Policy implementation, street-level bureaucracy, and the importance of discretion”, Public Management Review, Vol. 16 No. 4, pp. 527-547.

Tummers, L.G., Vermeeren, B., Steijn, B. and Bekkers, V. (2012), "Public professionals and policy implementation”, Public Management Review, Vol. 14 No. 8, pp. 1041-1059.

Tummers, L.G., Bekkers, V., Vink, E. and Musheno, M. (2015), "Coping during public service delivery: a conceptualization and systematic review of the literature", Journal of Public Administration Research and Theory, Vol. 25 No. 4, pp. 1099-1126.

Tuurnas, S., Stenvall, J. and Rannisto, P. (2016), "The impact of co-production on frontline accountability: the case of the conciliation service", International Review of Administrative Sciences, Vol. 82 No. 1, pp. 131-149.

van Oorschot, W. (2000), "Who should get what, and why? On deservingness criteria and the conditionality of solidarity among the public", Policy and Politics, Vol. 28 No. 1, pp. 33-48.

Van Parys, L. and Struyven, L. (2018), "Interaction styles of street-level workers and motivation of clients: a new instrument to assess discretion-as-used in the case of activation of job seekers", Public Management Review, Vol. 20 No. 11, pp. 1702-1721.

Vink, E., Tummers, L.G., Bekkers, V.J.J.M. and Musheno, M. (2015), "Decision-making at the frontline: exploring coping with moral conflicts during public service delivery", in Lewis, J. and Considine, M. (Eds), Making Public Policy Decisions, Routledge, London, pp. 112-128. 
Zacka, B. (2017), When the State Meets the Street, Public Service and Moral Agency, Belkamp Press, Cambridge.

\section{About the authors}

Daniela Leonardi, PhD in Applied Sociology and Social Research Methodology, is Research Fellow at the University of Parma. Her research focuses on Welfare, Social Exclusion, Public Policy Implementation, Homelessness. Her most recent publication is Leonardi, D. and Stefani, S. (2021), "The pandemic and homeless people in the Turin area: the level of housing adequacy shapes experiences and well-being", Housing, Care and Support, Vol. ahead-of-print No. ahead-of-print. doi: 10.1108/HCS-03-2021-0006.

Rebecca Paraciani, $\mathrm{PhD}$ in Sociology and Social Research, is research fellow at the Università Cattolica del Sacro Cuore (Milan) and teaching assistant at the University of Bologna. Her research focuses on street-level bureaucracy, public policy implementation, welfare services and organizational analysis. She has published in social and public policy journals, such as Journal of Public Policy, Sociological Quarterly and Politiche Sociali/Social Policies.

Dario Raspanti, PhD in Economic Sociology, is Research Fellow at the Department of Social and Political Sciences of the University of Florence. His research interests are labour market policy, public employment service, organizational sociology and creativity. His most recent publication is Raspanti and Saruis (2021). Trapped into Reverse Asymmetry: Public Employment Services Dealing with Employers. Journal of Social Policy, published online, pp. 1-18. Dario Raspanti is the corresponding author and can be contacted at: dario.raspanti@unifi.it

\section{SLBs' strategies within relational asymmetries}

For instructions on how to order reprints of this article, please visit our website: 